\title{
Acquired resistance to EGFR tyrosine kinase inhibitors in cancer cells is mediated by loss of IGF-binding proteins
}

\author{
Marta Guix, ${ }^{1}$ Anthony C. Faber, ${ }^{2}$ Shizhen Emily Wang,, ${ }^{3,4}$ Maria Graciela Olivares,, \\ Youngchul Song, ${ }^{2}$ Sherman Qu, ${ }^{1}$ Cammie Rinehart, ${ }^{1}$ Brenda Seidel, ${ }^{5}$ \\ Douglas Yee, ${ }^{5}$ Carlos L. Arteaga, ${ }^{1,3,4}$ and Jeffrey A. Engelman ${ }^{2}$

\begin{abstract}
1Department of Medicine, Vanderbilt University School of Medicine, Nashville, Tennessee, USA
2Massachusetts General Hospital Cancer Center, Harvard Medical School, Charlestown, Massachusetts, USA. ${ }^{3}$ Department of Cancer Biology and ${ }^{4}$ Breast Cancer Research Program, Vanderbilt-Ingram Comprehensive Cancer Center, Vanderbilt University School of Medicine, Nashville, Tennessee, USA. ${ }^{5}$ University of Minnesota Cancer Center, Minneapolis, Minnesota, USA
\end{abstract}

\begin{abstract}
Although some cancers are initially sensitive to EGFR tyrosine kinase inhibitors (TKIs), resistance invariably develops. We investigated mechanisms of acquired resistance to the EGFR TKI gefitinib by generating gefitinibresistant (GR) A431 squamous cancer cells. In GR cells, gefitinib reduced phosphorylation of EGFR, ErbB-3, and Erk but not Akt. These cells also showed hyperphosphorylation of the IGFI receptor (IGFIR) and constitutive association of IRS-1 with PI3K. Inhibition of IGFIR signaling disrupted the association of IRS-1 with PI3K and restored the ability of gefitinib to downregulate PI3K/Akt signaling and to inhibit GR cell growth. Gene expression analyses revealed that GR cells exhibited markedly reduced IGF-binding protein 3 (IGFBP-3) and IGFBP-4 RNA. Addition of recombinant IGFBP-3 restored the ability of gefitinib to downregulate PI3K/Akt signaling and to inhibit cell growth. Finally, gefitinib treatment of mice with A431 xenografts in combination with an IGFIR-specific monoclonal antibody prevented tumor recurrence, whereas each drug given alone was unable to do so. These data suggest that loss of expression of IGFBPs in tumor cells treated with EGFR TKIs derepresses IGFIR signaling, which in turn mediates resistance to EGFR antagonists. Moreover, combined therapeutic inhibition of EGFR and IGFIR may abrogate this acquired mechanism of drug resistance and is thus worthy of prospective clinical investigation.
\end{abstract}

\section{Introduction}

EGFR is a member of a family of closely related growth factor receptor tyrosine kinases (RTKs) that includes EGFR (ErbB-1), HER2/neu (ErbB-2), HER3 (ErbB-3), and HER4 (ErbB-4). Upon ligand binding, these receptors homo- and/or heterodimerize, and this leads to subsequent activation of intracellular signaling cascades such as the PI3K/Akt, Raf/MEK/Erk, and STAT signaling pathways. Small molecule EGFR tyrosine kinase inhibitors (TKIs) such as gefitinib (Iressa; AstraZeneca International) and erlotinib (Tarceva; OSI Pharmaceuticals) have been evaluated in clinical trials for patients with non-small cell lung cancer (NSCLC). Both agents cause partial responses in 10\%-20\% of all NSCLC patients (1-4). Tumors that possess activating mutations and/or amplification of the EGFR locus appear to be particularly sensitive to EGFR TKIs (5-11). A large randomized clinical trial demonstrated that erlotinib improves the overall survival of patients with cancers that have high EGFR copy numbers (12). TKI-sensitive cancers are unique in that several downstream signaling pathways promoting tumor cell survival, especially the PI3K pathway, are primarily regulated by EGFR activity (reviewed in ref. 13).

Nonstandard abbreviations used: GR, gefitinib resistant; IGFBP, IGF-binding protein; IGFIR, IGFI receptor; MTS, 3-(4,5-dimethylthiazol-2-yl)-5-(3-carboxymethoxyphenyl)-2-(4-sulfophenyl)-2H-tetrazolium; NSCLC, non-small cell lung cancer; RTK, receptor tyrosine kinase; TKI, tyrosine kinase inhibitor

Conflict of interest: Carlos Arteaga receives research support from Merck.

Citation for this article: J. Clin. Invest. 118:2609-2619 (2008). doi:10.1172/JCI34588.
Acquired resistance to EGFR TKIs occurs in NSCLC patients who initially respond to TKI treatment but whose cancer then progresses. This acquired resistance has been associated with the development of a secondary mutation in EGFR, T790M, analogous to those observed in BCR-Abl and KIT in imatinib-resistant chronic myelogenous leukemia and gastrointestinal stromal cell tumors, respectively (14-17). Initial studies have identified the T790M mutation in approximately $50 \%$ of cancers with acquired resistance to EGFR TKIs $(15,18-21)$.

Recently, amplification of MET, an RTK, was identified as another mechanism of acquired resistance $(21,22)$. Of note, when 3 different EGFR mutant cancer cell lines were made resistant to EGFR TKIs in vitro, 2 resistant cell lines developed T790M mutations and another developed MET amplification $(21,23,24)$. This highlights the capacity for laboratory models to identify the clinically relevant mechanisms of drug resistance. However, clinical and laboratory studies evaluating resistance to EGFR antagonists have focused almost exclusively on EGFR mutant lung cancers. Few studies have investigated resistance mechanisms in cancers with amplified wild-type EGFR even though patients bearing these cancers appear to exhibit a survival benefit from EGFR TKIs $(11,12)$.

Previous laboratory investigations have demonstrated that continued activation of the PI3K network is sufficient to confer resistance to EGFR TKIs. Accordingly, several models of acquired resistance demonstrate continued signaling along the PI3K pathway despite TKI treatment $(21,23-26)$. Our previous studies demonstrated that gefitinib-sensitive NSCLC cell lines 


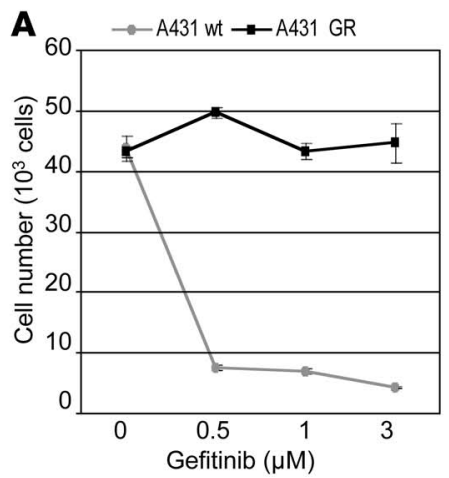

D
B

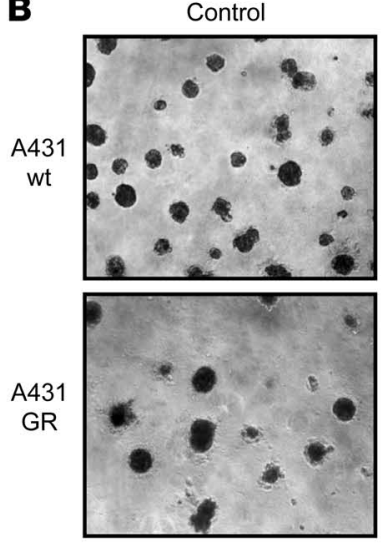

Gefitinib $1 \mu \mathrm{M}$

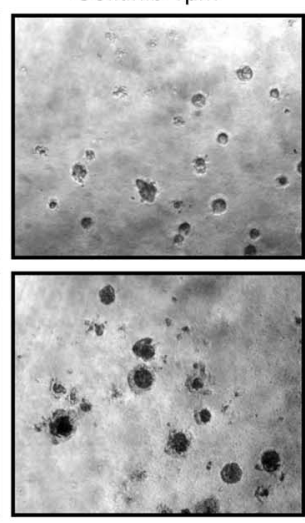

C

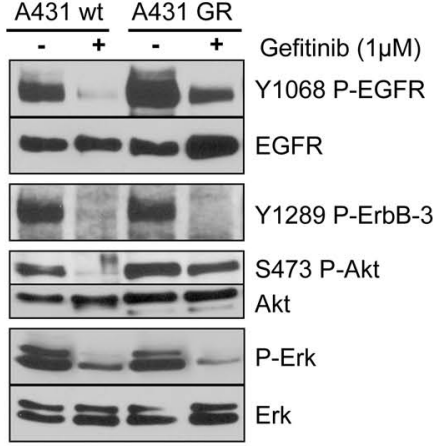

E

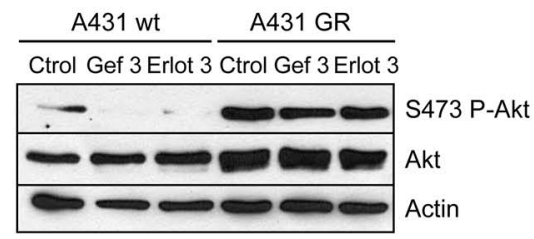

Figure 1

A431 GR cells maintain PI3K/Akt signaling in the presence of gefitinib and remain sensitive to PI3K inhibitors. (A) Parental and A431 GR cells were grown for 72 hours in $0.5 \%$ FBS containing medium with or without gefitinib at the indicated $\mu \mathrm{M}$ concentrations. Cell number was determined in a Coulter Counter. Each data point represents the mean \pm SD of 3 wells. (B) Parental and A431 GR cells were grown in Matrigel in the absence or presence of gefitinib $(1 \mu \mathrm{M})$. Pictures were taken after 10 days. Original magnification, $\times 10$. (C) Parental and A431 GR cells were treated for 6 hours in growth medium containing $1 \mu \mathrm{M}$ gefitinib. Whole-cell lysates were prepared and probed in immunoblots with the indicated antibodies. (D) Parental and GR cells were treated with control, gefitinib $(3 \mu \mathrm{M})$, or erlotinib $(3 \mu \mathrm{M})$, and the extracts were probed with the indicated antibodies. (E) Cell growth assays were performed as in A. Cells were treated with the indicated drugs and concentrations. (Gef, gefitinib; Erlot, erlotinib; LY, LY294002). Student's $t$ test was used for statistical comparisons. Error bars represent SD.

are distinct in that they specifically utilize ErbB-3 to activate the PI3K/Akt pathway (27). This finding resulted from comparing tyrosyl phosphoproteins that coprecipitate with PI3K in gefitinib-sensitive and -resistant NSCLC lines. In fact, MET amplification causes resistance because it phosphorylates ErbB-3, which in turn activates PI3K (21). However, other mechanisms that EGFR TKI-sensitive cancers adopt to activate PI3K as they become resistant remain to be identified.

In this study, we modeled acquired resistance to EGFR TKIs using the A431 cell line, which harbors wild-type EGFR gene amplification. We had previously determined that, similarly to all other TKI-sensitive cell lines, A431 cells mainly utilize ErbB-3 to activate PI3K (27). The gefitinib-resistant A431 cells, A431 GR, continue to downregulate $\mathrm{p}$-Erk in response to TKIs but maintain PI3K signaling in the presence of gefitinib. Immunoprecipitating PI3K, we observed that the resistant cells adopted the IGFIR pathway in addition to EGFR/ErbB-3 to activate PI3K. Concomitant inhibition of both EGFR and IGFIR was required to abort PI3K signaling, and treatment of the resistant cells with an IGFIR inhibitor restored their sensitivity to EGFR TKIs. Gene expression profiles of the resistant cells suggested that their increased
IGFIR activation was due to downregulation of IGF-binding proteins (IGFBPs). Restoration of IGFBP-3 reverted the GR phenotype. Importantly, treatment of tumor xenografts derived from parental A431 cells with combination EGFR and IGF1 receptor (IGFIR) blockade thwarted the emergence of resistance that occurred when tumors were treated with single-agent gefitinib. Similarly, another model of acquired resistance to gefitinib was developed using another gefitinib-sensitive wild-type EGFR cell line, the head and neck HN11 cells. The resistant HN11 cells also maintained Akt phosphorylation in the presence of gefitinib, and resistance was again overcome by combined EGFR and IGFIR inhibition. Collectively, these findings suggest a new therapeutic strategy for overcoming resistance to EGFR inhibitors in cancers that depend on activated wild-type EGFR and identify loss of IGFbinding proteins as a potential surrogate marker for activation of the IGFIR pathway in these tumors.

\section{Results}

A431 GR cells remain sensitive to PI3K inhibitors. A431 GR cells were generated in culture by growing A431 cells in increasing concentrations of gefitinib over a period of several months up to 


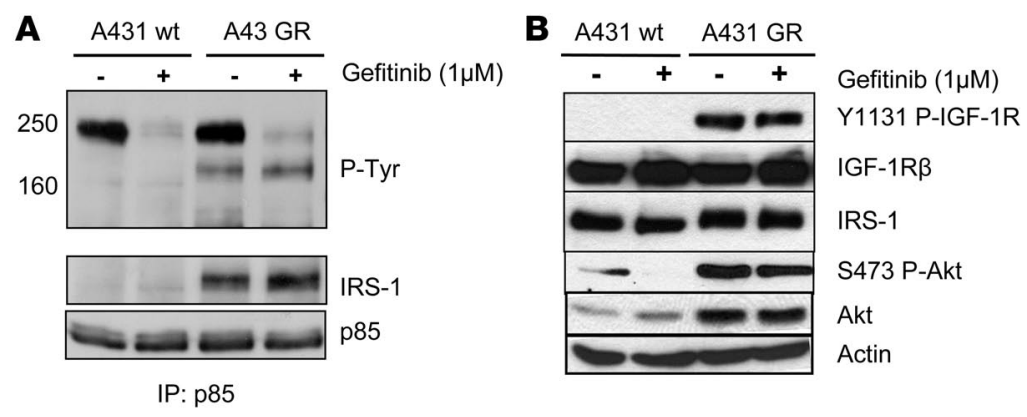

Figure 2

IRS-1 associates with PI3K in GR but not sensitive A431 cells. (A) Parental and A431 GR cells were treated with or without $1 \mu \mathrm{M}$ gefitinib for 6 hours. Cell lysates were subjected to immunoprecipitation with an anti-p85 antibody followed by Western blot analysis with an anti-p-Tyr antibody. The blots were then stripped and reprobed with antibodies against IRS-1 and p85. (B) The parental and A431 GR cells were treated as in $\mathbf{A}$, and the extracts were probed with antibodies against the indicated proteins. Note that IGFIR phosphorylation is substantially greater in the A431 GR cells.

a final concentration of $3 \mu \mathrm{M}$, similarly to previously described methods $(21,24)$. When grown in tissue culture plates for 3 days under low-serum conditions ( $0.5 \%$ FBS), there was no reduction in the number of A431 GR cells at gefitinib concentrations up to $3 \mu \mathrm{M}$, whereas only approximately $10 \%$ of parental A431 cells survived after exposure to $0.5 \mu \mathrm{M}$ gefitinib (Figure 1A). A $3 \mathrm{D}$ growth assay in Matrigel demonstrated that A431 GR cells formed large solid colonies in the presence of $1 \mu \mathrm{M}$ gefitinib, whereas this same drug concentration markedly impaired colony growth of parental A431 cells (Figure 1B). Of note, the GR cells were cross-resistant to the EGFR TKI erlotinib $(3 \mu \mathrm{M})$ and the EGFR monoclonal antibody cetuximab $(10 \mu \mathrm{g} / \mathrm{ml})$ (Supplemental Figure 1; supplemental material available online with this article; doi:10.1172/JCI34588DS1).

To investigate the underlying mechanism of resistance to the EGFR TKI, we probed lysates from both parental and GR cells treated for 6 hours with gefitinib. As shown in Figure 1C, gefitinib treatment effectively downregulated ErbB-3 phosphorylation in both the parental and GR cells. Although ErbB3 phosphorylation was downregulated by gefitinib, Akt phosphorylation was not suppressed by gefitinib or erlotinib in the resistant cells (Figure 1, C and D). As we had previously identified ErbB-3 as the protein that directly activates PI3K in A431 cells, these results suggested that the resistant cells adopted a new mechanism for activating PI3K/Akt. Of note, in contrast to the persistent Akt phosphorylation, Erk phosphorylation was downregulated by gefitinib in the resistant cells. This is different from other models of acquired resistance that have persistent activation of both the Akt and Erk pathways in the presence of gefitinib $(21,24)$. Of note, the protein levels of the phosphatase PTEN were similar in both cell types, as measured by immunoblot analysis (Supplemental Figure 2).

To determine whether the persistent activation of Akt in A431 GR cells correlated with resistance to EGFR TKI treatment, A431 GR cells were treated for 72 hours in low-serum conditions with either gefitinib, the MEK1/2 inhibitor CI-1040 (28), or the PI3K inhibitor LY294002. Treatment with CI-1040 (1 $\mu \mathrm{M})$ completely blocked p-Erk (data not shown) but had no effect on cell number when compared with gefitinib (Figure 1E). On the other hand, treatment with LY294002 $(50 \mu \mathrm{M})$ resulted in complete abrogation of Akt phosphorylation and inhibition of cell proliferation (Figure 1E). Similar results were obtained with the more potent PI3K inhibitor PI-103 (29) (Supplemental Figure 3).

IRS-1 associates with PI $3 \mathrm{~K}$ in GR but not parental A431 cells. Class I PI3K appears to be the major PI3K activated by growth factor receptors in the pathogenesis of human epithelial cancers (30). PI3K is activated through direct binding of the $\mathrm{SH} 2$ domains of the p85 regulatory subunit to activated RTKs or tyrosine-phosphorylated proteins. To determine how PI3K is activated in parental and A431 GR cells, p85 was immunoprecipitated from cells cultured in the presence or absence of gefitinib, and the antibody pulldowns were probed with an anti-phosphotyrosine antibody. In both cell lines, a major coprecipitating p-Tyr band at approximately $220 \mathrm{kDa}$ was observed, and this interaction was abrogated by gefitinib treatment (Figure 2A). This p-Tyr band was recognized by an ErbB-3 antibody when the membrane was reprobed, as we have reported previously (data not shown) (27). Interestingly, a new p-Tyr band migrating at approximately $180 \mathrm{kDa}$ coprecipitated with PI3K only in the GR cells. This interaction was not blocked by gefitinib, and the approximately $180-\mathrm{kDa}$ protein was identified as IRS-1, a well-known substrate of the IGFIR that activates PI3K when tyrosine phosphorylated (30) (Figure 2A). We next investigated the upstream activator of IRS-1 in GR cells. As shown in Figure 2B, the IGFIR was highly phosphorylated in only the GR cells, irrespective of gefitinib treatment.

Blockade of IGFIR in combination with gefitinib inbibits p-Akt and cell growth of A431-GR cells. These results suggested that the IGFIR/IRS-1 pathway might play a role in maintaining PI3K activity in the presence of gefitinib. Many drugs targeting the IGFIR are under clinical development. These include low MW ATP mimetics that bind to the intracellular kinase domain and thus block the receptor's catalytic activity (i.e., AEW541) (31) as well as antibodies directed against the extracellular domain of the IGFIR that block ligand binding and downregulate cell-surface receptors (e.g. Mk-0646) (32). Therefore, we treated cells with gefitinib or AEW541 alone or both drugs in combination. As shown in Figure 3A, Akt phosphorylation is blocked substantially when the cells are treated with both inhibitors but not either alone. Of note, this inhibition was observed both in low and high serum. However, single-agent gefitinib treatment leads to greater loss of Akt phosphorylation in low serum likely because fetal bovine serum is a rich source of IGF ligand (33). Treatment of A431 GR cells with the IGFIR antibody (Mk-0646) or AEW541 resulted in loss of PI3K binding to IRS-1 (Figure 3B) but did not affect binding to ErbB-3. Treatment with gefitinib ablated the interaction between PI3K and ErbB-3. Accordingly, combination treatment with both gefitinib and either of the IGFIR inhibitors was needed to disrupt the coupling of PI3K to both IRS-1 and ErbB-3 (Figure 3B) and thus effectively diminish Akt phosphorylation (Figure 3, A and B).

These results suggest that the A431 GR cells have acquired the IGFIR/IRS-1 pathway as an additional input into PI3K activation (Figure 3C) and that its inhibition is necessary to restore sensitivity to gefitinib. Thus, we next evaluated the effects of IGFIR inhibitors and gefitinib on growth of A431 GR cells. When grown in a $3 \mathrm{D}$ system using Matrigel, the combination of gefitinib and 
A
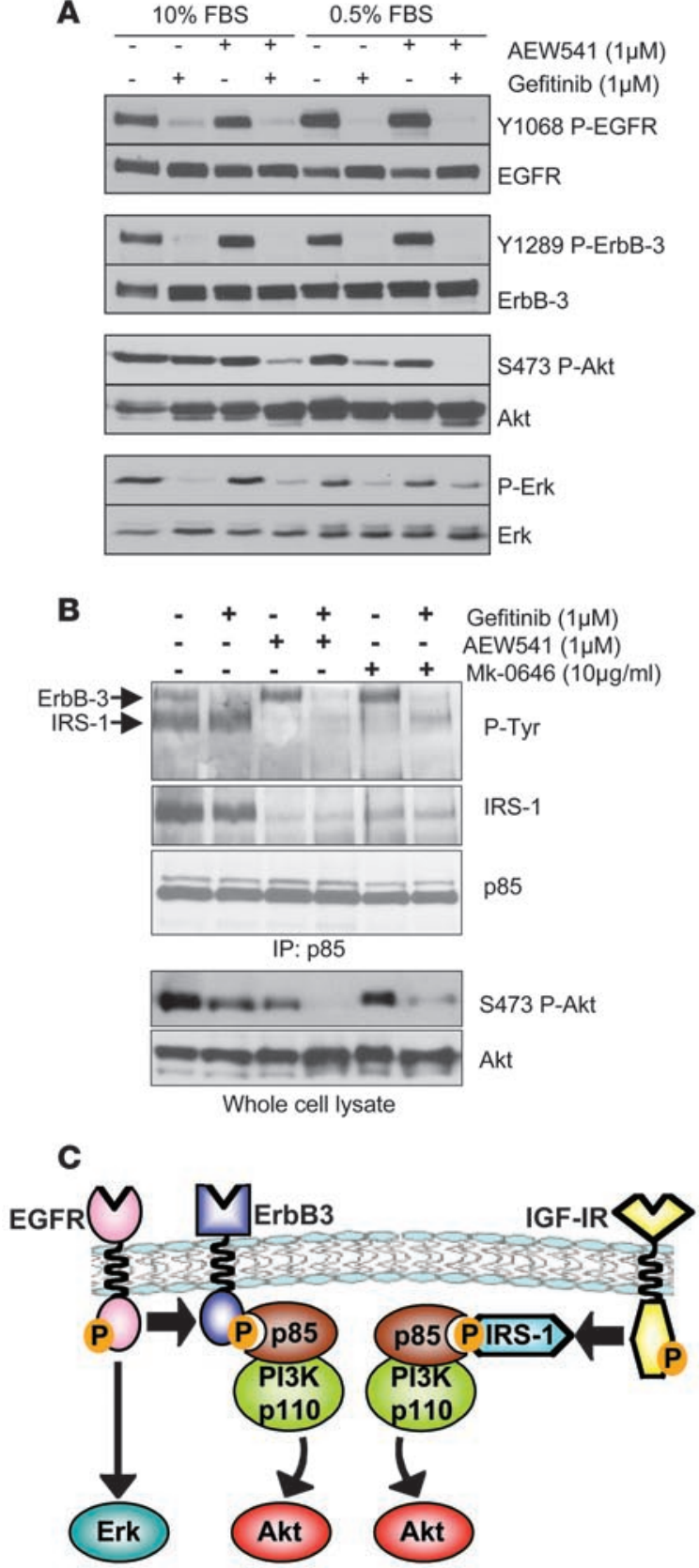

D
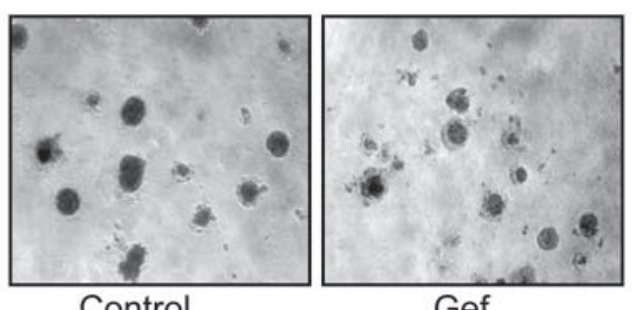

Control

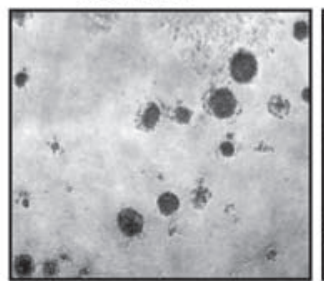

AEW541

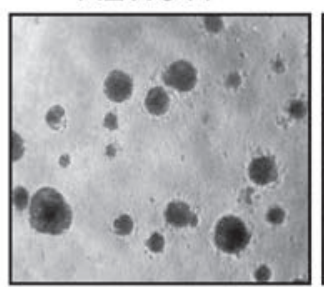

Mk-0646

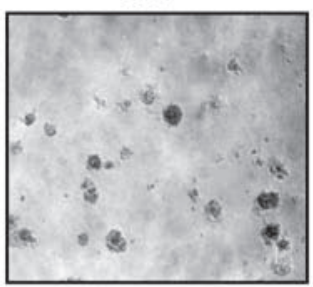

Gef + AEW541

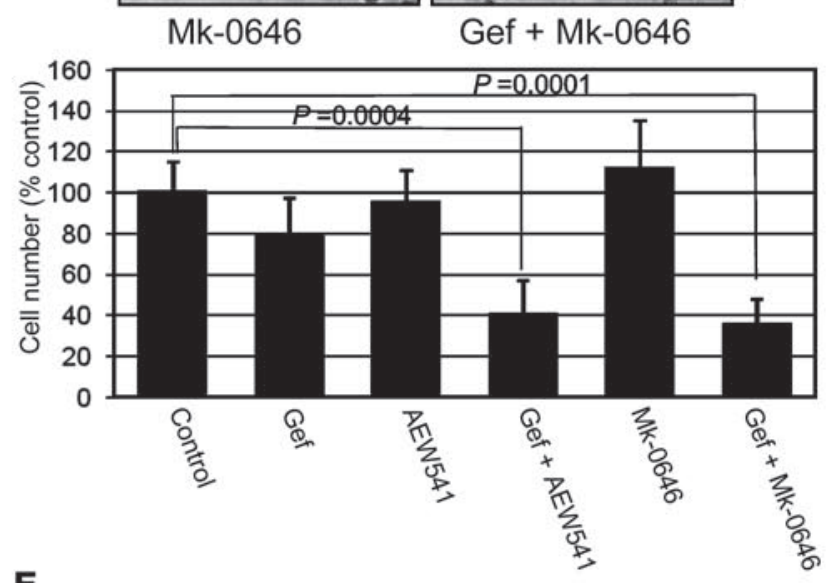

E

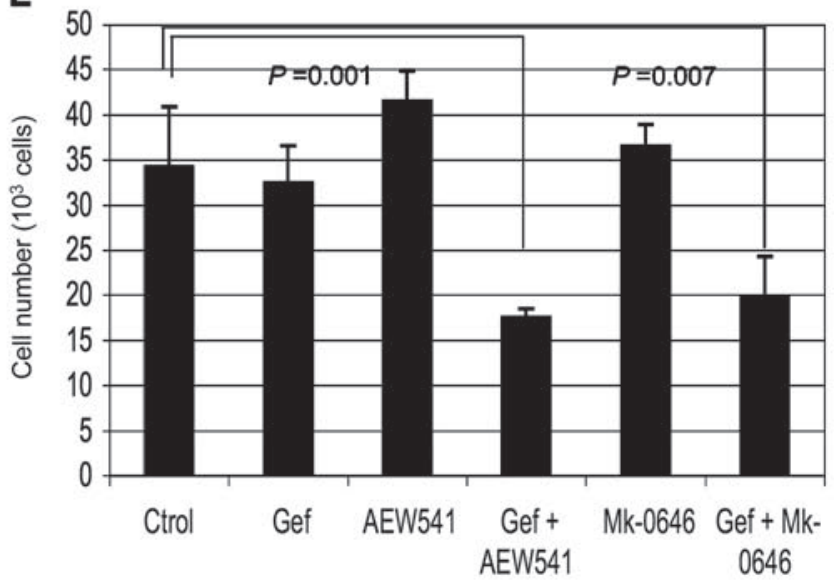




\section{Figure 3}

Blockade of IGFIR in combination with gefitinib inhibits PI3K/Akt signaling and cell growth. (A) A431 GR cells were treated with control, gefitinib $(1 \mu \mathrm{M})$, AEW541 $(1 \mu \mathrm{M})$, or gefitinib and AEW541 at the indicated concentrations in either full serum (10\% FBS) or low serum $(0.5 \%$ FBS $)$ for 6 hours. The cells were lysed and Western blots were probed with the indicated antibodies. (B) The A431 GR cells were treated with single-agent gefitinib, AEW541, Mk-0646, or combinations of gefitinib and AEW541 or gefitinib and Mk-0646 at the indicated concentrations for 6 hours. Cells were lysed as in Figure 2A, and the extracts were immunoprecipitated with an anti-p85 antibody. IPs were probed with the indicated antibodies. Extracts from the same lysates were probed with antibodies against p-Akt (Ser473) and total Akt. (C) A schematic depicting the 2 pathways leading to PI3K/Akt signaling in A431 GR cells: the EGFR/ErbB-3 and the IGFIR/IRS-1 pathways. (D) A431 GR cells were grown in Matrigel with or without gefitinib $(1 \mu \mathrm{M})$, AEW541 $(1 \mu \mathrm{M})$, Mk-0646 $(10 \mu \mathrm{g} / \mathrm{ml})$, or combinations of these drugs as specified. Photographs of the colonies were taken after 10 days. Original magnification, $\times 10$. Right panel shows cell numbers from Matrigel experiments. Cells were harvested by trypsinization and then counted. Cell numbers are represented as percentages of untreated cells. Bars represent the mean \pm SD of 3 wells. (E) A431 GR cells were grown in 12 -well plates in $0.5 \%$ FBS-containing medium for 72 hours with or without drugs (same concentrations as in $\mathbf{D}$ ) and harvested by trypsinization. Cell numbers were determined with a Coulter Counter. Bars represent the mean \pm SD of 3 wells. Student's $t$ test was used for statistical comparisons.

AEW541 or gefitinib and Mk-0646 markedly reduced colony size and number (Figure 3D). Similar results were obtained in monolayer growth assays (Figure 3E).

IGFBPs are downregulated in A431-GR cells. To investigate how the IGFIR pathway is activated in GR cells, we performed geneexpression profiling experiments. RNA was extracted from GR and parental A431 cells. The RNA was then hybridized to Human Genome U133 Plus 2.0 Affymetrix Microarray Chips, and gene expression was analyzed as described in Methods. Table 1 summarizes the differences observed in the IGFIR axis in the GR versus parental A431 cells expressed as fold change of individual probes for a given gene in the microarray (for complete microarray data, see Gene Expression Omnibus; accession number GSE10696). IGFBP-3 and IGFBP-4, proteins that are known to inhibit IGF-induced activation of the IGFIR and the IGF type 2 receptor (IGF2R), were downregulated in GR cells. The metalloprotease ADAM12 was upregulated. There were no changes observed in the expression levels of the 2 main IGFIR ligands, IGF1 and IGF2. Additionally, IGF-I and IGF-II protein levels measured from conditioned media from both cell lines confirmed that they were not significantly different between the 2 cell lines (Figure 4A).

To evaluate the protein expression of the IGFBPs, medium conditioned by parental and GR cells was separated under nonreducing conditions on SDS-PAGE, transferred to a membrane, and incubated with ${ }^{125}$ I-IGF-I. There was substantially more intense ${ }^{125}$ I-IGF-I binding in parental compared with GR cells at approximately 40 and $25 \mathrm{kDa}$, the MWs of IGFBP- 3 and IGFBP-4 respectively (Figure 4B). This ligand blot also suggests that IGFBP-3 is the predominant IGF-binding protein in A431 cells. The identity of the radioligand-binding bands was confirmed using specific IGFBP-3 and IGFBP-4 antibodies on similar samples of conditioned media as well as on whole-cell lysates from GR and parental A431 cells (Figure 4B).
These results raised the possibility that decreased expression of IGFBPs contributes to the increased activation of the IGFIR pathway in the A431 GR cells. Thus, we determined whether restoration of IGFBP-3 would reverse the resistant phenotype. A431 GR cells were treated with recombinant IGFBP-3, gefitinib, or a combination of the 2. As shown in Figure 4C, neither IGFBP-3 nor gefitinib alone substantially reduced cell growth. However, their combination had a marked inhibitory effect on cell growth. As expected, the combination of IGFBP-3 with gefitinib led to downregulation of Akt phosphorylation (Figure 4D), mimicking the effects of combined IGFIR and EGFR inhibition (Figure 3, A and B). In the A431 parental cells, we used shRNA to downregulate IGFBP-3 and found that this promoted only subtle resistance to gefitinib (Supplemental Figure 4). Thus, although loss of IGFBP-3 is necessary for resistance to gefitinib in the A431 GR cells (Figure 4, C and D), its loss alone is not sufficient to promote a complete resistance phenotype in A431 cells. Thus, factors other than only downregulation of IGFBP-3 (e.g., downregulation of IGFBP-4) are also likely contributors to resistance in A431 GR cells.

The data displayed thus far suggest that the A431 cells became resistant to gefitinib via activation of the IGFIR pathway. Thus, we hypothesized that addition of IGF-I ligand would be able to activate PI3K in the parental A431 cells in the presence of gefitinib and induce drug resistance. As shown in Figure 5A, treatment of the A431 cells with IGF-I maintained PI3K and mTOR (i.e., P-S6) activity in the presence of gefitinib. Interestingly, in the highly sensitive EGFR mutant HCC827 cells, although IGF activated IGFIR phosphorylation, it did not maintain Akt and $S 6$ phosphorylation in the presence of gefitinib (Figure 5A). Accordingly, addition of IGF-I conferred resistance to gefitinib in A431 cells but not in HCC827 cells as measured with a 72-hour 3-(4,5-dimethylthiazol2-yl)-5-(3-carboxymethoxyphenyl)-2-(4-sulfophenyl)-2H-tetrazolium (MTS) assay (Figure 5B).

Additionally, we developed an independent A431 cell line with acquired resistance to the EGFR antibody cetuximab (see Methods). Interestingly, in this resistant cell line, we found that there was also downregulation of IGFBP-3, and the cells were highly sensitive to combined EGFR and IGFIR inhibition (Supplemental Figure 5). We also generated an acquired resistance model from the head and neck cancer HN11 cells that have wild-type EGFR and are sensitive to gefitinib (Figure 6A). Similar to the A431 GR cells, Akt, but not Erk1/2, phosphorylation is maintained in the presence of gefitinib in the HN11 GR cells. In addition, treatment of the HN11 GR cells with a combination of gefitinib and AEW541 leads to a dramatic loss of Akt phosphorylation and cell viability at concentrations of less than $1 \mu \mathrm{M}$ of both drugs (Figure $6, \mathrm{~B}$ and C). There is loss of IGFBP-4 expression in the HN11 GR cells (Supplemental Figure 6), similar to that in the A431 GR cells. We did not detect expression of IGFBP-3 in the HN11 parental or GR cells (data not shown).

Inbibition of IGFIR abrogates the emergence of resistance to gefitinib. Finally, we tested to determine whether the addition of an IGFIR inhibitor would delay the development of resistance to gefitinib in parental A431 cells. Of note, we observed that a second independently developed GR A431 cell line, A431 GR2, also developed resistance via activation of IGFIR signaling (Supplemental Figure 7), suggesting that this is the major mechanism of escape from EGFR inhibitors utilized by A431 cells. When cells were chronically cultured in growth medium containing $1 \mu \mathrm{M}$ gefi- 
Table 1

Changes in expression levels of genes involved in the IGFIR pathway

$\begin{array}{lcc}\begin{array}{l}\text { Gene expression level } \\ \text { (GR vs. WT) }\end{array} & \text { Symbol } & \text { Description } \\ 2.53 & & \\ 5.89 & \text { ADAM12 } & \text { ADAM metallopeptidase domain 12 (meltrin } \alpha \text { ) } \\ 12.22 & \text { ADAM12 } & \text { ADAM metallopeptidase domain 12 (meltrin } \alpha \text { ) } \\ 12.88 & \text { ADAM12 } & \text { ADAM metallopeptidase domain 12 (meltrin } \alpha \text { ) } \\ -2.82 & \text { ADAM12 } & \text { ADAM metallopeptidase domain 12 (meltrin } \alpha \text { ) } \\ -2.44 & \text { IGF2R } & \text { Insulin-like growth factor 2 receptor } \\ -3.47 & \text { IGF2R } & \text { Insulin-like growth factor 2 receptor } \\ -3.25 & \text { IGFBP-3 } & \text { Insulin-like growth factor-binding protein 3 } \\ -3.06 & \text { IGFBP-3 } & \text { Insulin-like growth factor-binding protein 3 } \\ -6.15 & \text { IGFBP-4 } & \text { Insulin-like growth factor-binding protein 4 } \\ 2.32 & \text { IGFL1 } & \text { Insulin-like growth factor family member 1 } \\ 2.52 & \text { IMP-3 } & \text { Insulin-like growth factor II mRNA-binding protein 3 } \\ 2.78 & \text { IMP-3 } & \text { Insulin-like growth factor II mRNA-binding protein 3 } \\ 3.03 & \text { IMP-3 } & \text { Insulin-like growth factor II mRNA-binding protein 3 } \\ 3.57 & \text { INSIG1 } & \text { Insulin-induced gene 1 } \\ 2.27 & \text { INSIG1 } & \text { Insulin-induced gene 1 } \\ 4.47 & \text { INSR } & \text { Insulin receptor } \\ 7.09 & \text { INSR } & \text { Insulin receptor } \\ -2.11 & \text { INSR } & \text { Insulin receptor } \\ & \text { IRS1 } & \text { Insulin receptor substrate 1 }\end{array}$

CDNA microarray data summary of the main changes in expression levels of genes involved in the IGFIR pathway, comparing GR versus parental A431 cells. Each value shown for a specific gene represents a unique probe. AFold change. BPositive values: higher in GR compared with WT cells; negative values: lower in GR compared with WT cells.

tinib, resistance emerged within 6 to 8 weeks and cells slowly resumed their growth. However, when AEW541 was added to gefitinib during cell selection, only a few cells survived after prolonged treatment, and more prolonged exposure to the drugs resulted in death of all cells (Figure 7A). Of note, the addition of the MEK inhibitor CI-1040 at $1 \mu \mathrm{M}$ did not delay the emergence of GR cells. These findings support the hypothesis that EGFR TKI resistance in A431 cells is mainly driven by IGFIR-mediated activation of PI3K/Akt.

A431 xenografts are highly sensitive to gefitinib treatment. However, some tumors can develop resistance during drug treatment or resume growth shortly after exposure to the drug is stopped (34). We hypothesized that the addition of an IGFIR inhibitor to gefitinib would prevent the development of resistance and/or delay tumor recurrences. Mice bearing A431 xenografts were randomized to no therapy, gefitinib, Mk-0646, or the combination of both drugs for 30 days. Treatment with gefitinib alone induced a complete response in all mice after approximately 18 days of treatment. However, 2 out of 7 mice had their tumors progress while still receiving gefitinib, and 3 additional mice had their tumors recur shortly after stopping the drug, so only 2 mice from this cohort were tumor free at the termination of the experiment. All mice treated with Mk-0646 experienced a short-lived partial response after the first week of therapy but then had tumor recurrence during treatment. However, in the combination group, all mice experienced a complete response, and only 1 mouse had a recurrent tumor more than 2 months after discontinuation of therapy (Figure 7B). Additionally, we observed that the combination of therapies was much more potent at inhibiting Akt phosphorylation in vivo (Supplemental Figure 8). This was consistent with the combination's increased proapoptotic and antiproliferative activity as measured by TUNEL staining and BrdU incorporation, respectively (Supplemental Figure 9). Attempts to do this experiment with AEW541 were not successful because, at the recommended dose, the small molecule induced a greater than $30 \%$ loss of body weight and mouse death. Overall, these data suggest that initial treatment with a regimen that thwarts a known escape mechanism can markedly inhibit the emergence of drug resistance.

\section{Discussion}

Although many cancers initially respond to EGFR kinase inhibitors, they invariably become resistant to this therapy. To date, most studies evaluating acquired resistance mechanisms to EGFR TKIs have focused on NSCLCs with EGFR mutations. In those highly sensitive cancers, laboratory models and patient specimens have identified secondary mutations in $E G F R$ (T790M) and amplification of the $M E T$ oncogene as mechanisms of acquired resistance $(14,15,19-23)$. However, it is widely appreciated that some cancers with amplified wild-type EGFR also derive significant clinical benefit from EGFR TKIs, but there has been a paucity of investigations into potential resistance mechanisms in this population $(11,12)$. In this study, we developed a drug-resistant model of the amplified EGFR wild-type A431 cells. Unlike the parental cells, the A431 GR cells maintain PI3K signaling in the presence of gefitinib. By immunoprecipitating PI3K, we determined that PI3K signaling is maintained in the resistant cells by an activated IGFIR pathway. In these cells, this pathway appears to be activated at least in part by loss of IGFBP-3. Importantly, treating the A431 GR cells with a combination of an EGFR and an IGFIR inhibitor was sufficient to reverse the resistant phenotype. Additionally, we found that resistance to another EGFR wild-type cell line, HN11, also maintained Akt phosphorylation in the presence of gefitinib and was effectively treated with a combination of EGFR and IGFIR inhibitors.

Many studies have suggested that downregulation of PI3K signaling is required for RTK inhibitors to work effectively (24, $26,27,35-37)$. For example, EGFR-amplified cells with PTEN loss have intrinsic resistance to EGFR inhibitors, even though inhibiting EGFR led to downregulation of Erk signaling (26, 35). Furthermore, ectopic expression of an oncogenic PI3K mutant in a highly sensitive EGFR mutant cell line (HCC827) is sufficient to confer resistance to gefitinib (24). Interestingly, in cell-line models of acquired resistance to EGFR inhibitors using EGFR mutant cell lines HCC827 and H3255, both the Erk and PI3K pathways are maintained in the resistant cells (via a T790M mutation and MET amplification, respectively) $(21,24)$. However, unlike those models, the A431 GR and HN11 GR in the study herein continued to downregulate Erk in response to gefitinib but maintained PI3K/Akt signaling. Thus, these models further support the notion that maintenance of PI3K signal- 
A

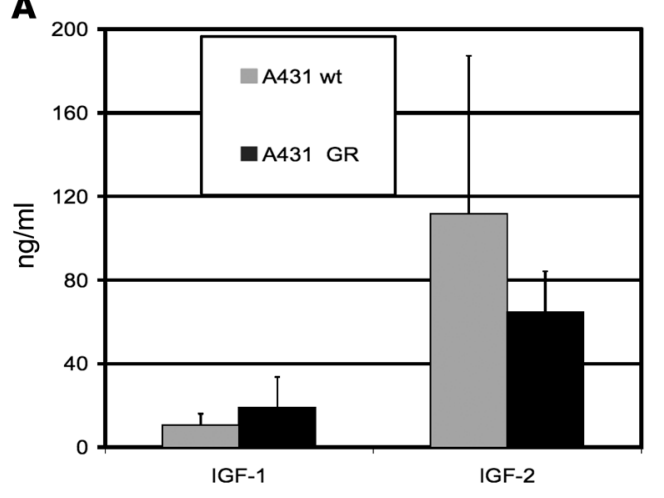

B

\section{Western ligand blot on C.M.}

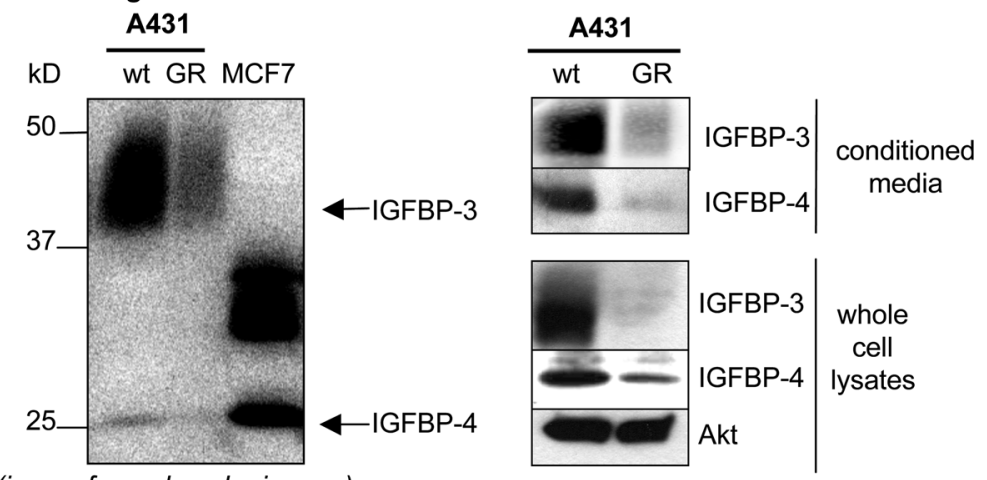

C

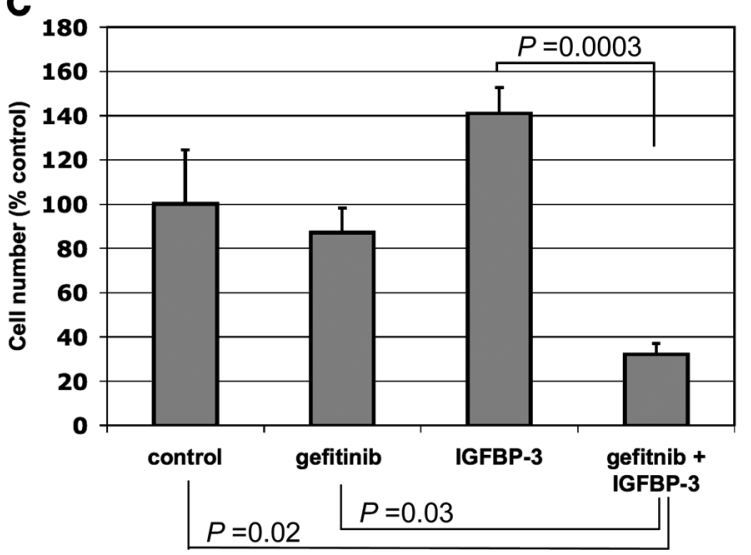

D

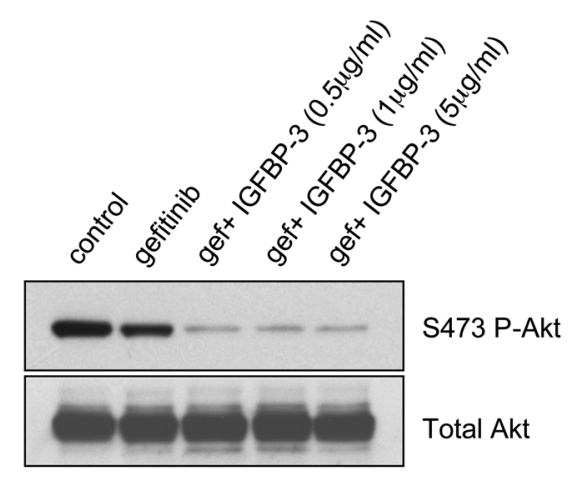

Figure 4

IGFBPs are downregulated in GR cells. (A) Parental and A431 GR cells (106 cells) were incubated for 24 hours in serum-free medium. The conditioned medium (C.M.) was concentrated by ultrafiltration, and IGF-I and IGF-II levels were determined by immunoassay as indicated in Methods. Bars represent the mean \pm SD of 3 experiments. (B) Left panel: conditioned medium from $2 \times 10^{6}$ parental and A431 GR cells was collected after 24 hours incubation and concentrated 20-fold by ultrafiltration. Medium was subjected to electrophoresis under nonreducing conditions, transferred to a nitrocellulose membrane, and incubated with ${ }^{125}-\mathrm{IGF}-\mathrm{I}$ overnight at $4^{\circ} \mathrm{C}$. Signal was captured with a phosphorimager. Human serum and MCF-7 cells were used as positive controls for ${ }^{125}$ I-IGF-I binding and IGFBP-4. Right panel: conditioned medium or $50 \mu \mathrm{g}$ total protein from whole-cell lysates was subjected to immunoblot analysis with IGFBP-3, IGFBP-4, or Akt antibodies. (C) A431 GR cells were grown in 12-well plates in $0.5 \%$ FBS-containing medium for 72 hours with or without gefitinib $(1 \mu \mathrm{M})$ and/or IGFBP-3 ( $1 \mu \mathrm{g} / \mathrm{ml})$ and harvested by trypsinization. Cell numbers were determined with a Coulter Counter. Error bars represent the mean \pm SD of 3 wells. Student's $t$ test was used for statistical comparisons. (D) A431 GR cells were treated with vehicle or gefitinib $(1 \mu \mathrm{M}) \pm$ IGFBP-3 at the indicated concentrations for 6 hours. Cell lysates were prepared and analyzed with Western blots using the indicated antibodies.

ing is essential for a cancer cell to become resistant to EGFR TKIs. Indeed, in these models, the IGFIR pathway was sufficient to maintain p-Akt in the presence of gefitinib. Surprisingly, in the parental A431 cells but not the more highly sensitive EGFR mutant HCC827 cells, addition of exogenous IGF-I ligand was able to maintain Akt, Erk, and mTOR activity in the presence of gefitinib. The inability of exogenous IGF-I to activate these downstream pathways in the mutant EGFR HCC827 cells despite evidence of ligand-induced IGFIR phosphorylation is intriguing and requires additional investigation.

The parental A431 cells can be made resistant to EGFR TKIs by treatment with exogenous IGF-I. Thus, it was not surprising that the sensitivity of these cells was affected by the presence or absence of fetal bovine serum, as this is a rich source of IGFs. In fact, as shown in Figure $3 \mathrm{~A}$, in the absence of serum, gefitinib modestly inhibited Akt in the resistant cells. Importantly, the in vivo experiments demonstrated that under "physiologi- cal" conditions, the emergence of resistance was thwarted by initial treatment of the A431 xenografts with a combination of EGFR and IGFIR inhibitors (Figure 7B). Such a treatment paradigm has potential clinical ramifications. Perhaps, if patients are treated with therapies designed to combat potential mechanisms of resistance, as is done for infectious diseases such as tuberculosis and HIV, longer-term remissions would be achieved with combinatorial therapy delivered immediately after diagnosis. These results also imply that the testing of drugs that specifically block mechanisms of resistance to targeted therapies, such as IGFIR antagonists in this study, may not provide significant clinical activity when used as single agents but will be effective when used in combination.

It is noteworthy that IGFBP-3 expression is markedly downregulated in the A431 gefitnib-resistant cells. This result fits well the published correlation between EGFR and IGFBP-3 overexpression in esophageal cancers. According to this report, IGFBP-3 
A

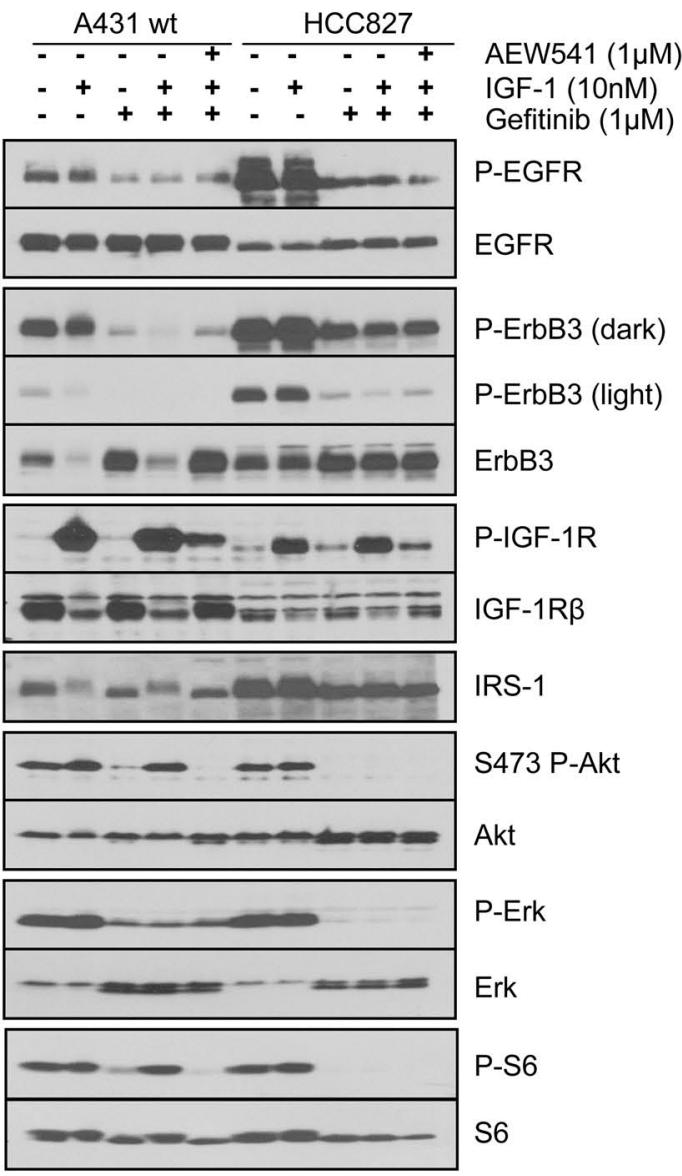

B
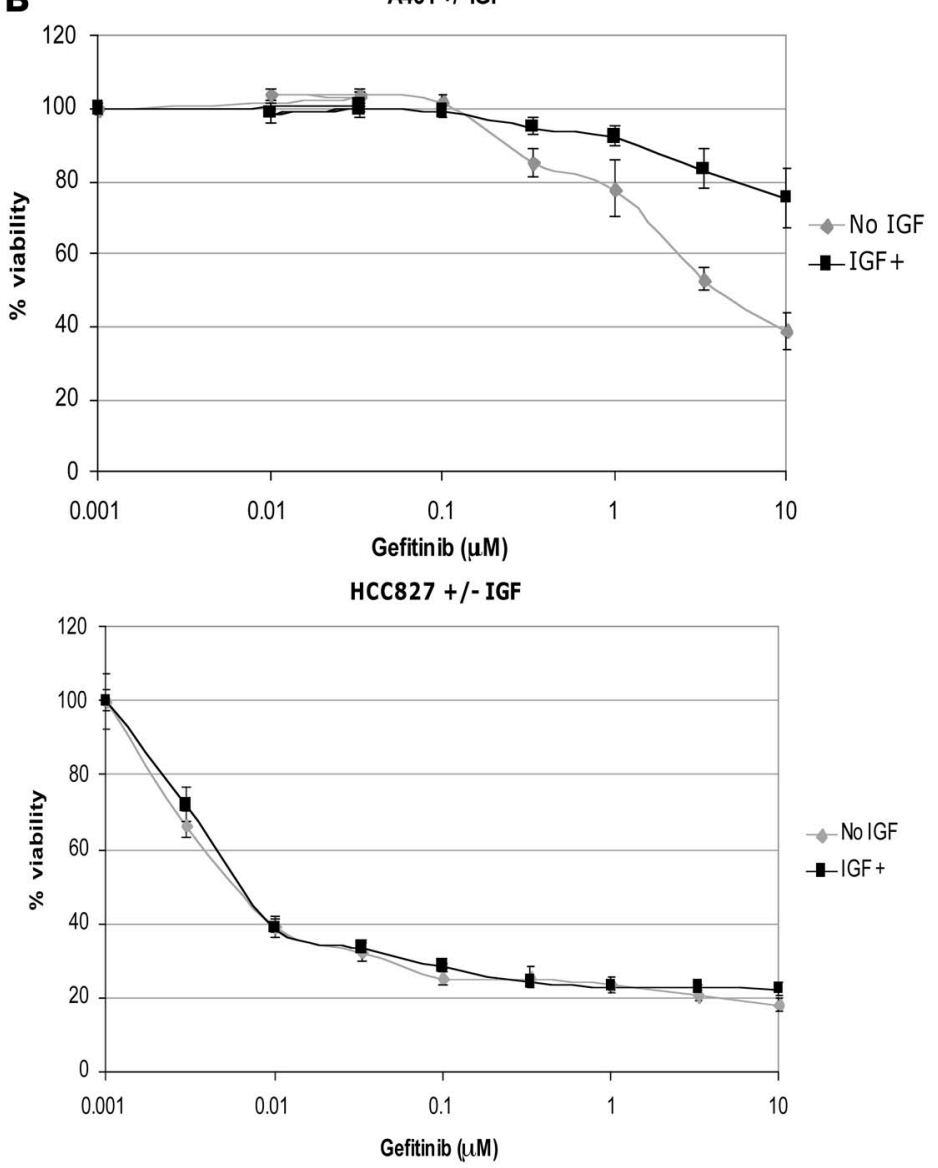

Figure 5

IGF-I activates PI3K/Akt and promotes gefitinib resistance in A431 cells but not in EGFR mutant HCC827 cells. (A) A431 and HCC827 cells were exposed to IGF-I (10 nM), gefitinib $(1 \mu \mathrm{M})$, AEW541 $(1 \mu \mathrm{M})$, or a combination as indicated for 6 hours. Cells were lysed and probed with the indicated antibodies. (B) A431 and HCC827 cells were subjected to a 72-hour MTS survival assay (see Methods) in increasing doses of gefitinib and in the presence or absence of $10 \mathrm{nM}$ IGF-I. Results are presented as percentage of survival compared with cells grown in the absence of gefitinib. Experiments with each concentration of gefitinib were performed 6 times and the mean \pm SD are shown.

expression is at least partially under the control of EGFR activity, although this mechanism is not completely understood. Further, EGF stimulation in A431 cells upregulates IGFBP-3, whereas treatment with AG1478, an EGFR TKI, results in its downregulation (38). These observations are consistent with our findings that A431 GR cells, which are developed under chronic EGFR inhibition, have suppressed IGFBP-3 expression. This may account for the cells' adaptation to utilizing the IGFIR pathway to activate PI3K/AKT signaling when grown under conditions of EGFR inhibition. In our study, reexposure of the A431 GR cells to IGFBP-3 resensitized both the PI3K pathway and cell survival to the effects of gefitinib. IGFBP-3 has long been established as a potent negative regulator of IGFIR activation and is believed to block ligand from binding to receptor, although it may also have IGF-independent antiproliferative activities (39). IGFBP-3 has been shown to inhibit the proliferation and invasiveness of cancer cells (40-42). Finally, treatment with recombinant human IGFBP-3 increases the sensitivity of BT474/HerR (Herceptin resistant) cells to trastuzumab in vitro and has shown potent single-agent activity in mice bearing trastuzumab-resistant xenografts (43).
The results from a recent phase I study evaluating an antiIGFIR antibody in patients with advanced human malignancies also highlights the primary role of IGFBP-3 in regulating IGFIR signaling (44). In this study, there was 1 impressive complete response that occurred in a patient with Ewing sarcoma. This is particularly intriguing because the EWS/FLI-1 translocation characteristic of Ewing sarcoma leads to loss of IGFBP-3 expression via direct transcriptional repression by the resulting fusion protein (45). Thus, it is tempting to speculate that these molecular events lead to activation of and "addiction" to IGFIR and thereby explain the complete response observed in this clinical trial. It will be interesting to learn whether loss of IGFBP expression serves as a marker of addiction to IGFIR signaling in other cell lines and tumor types as well.

Unlike EGFR T790M mutation and MET amplification, activation of IGFIR pathway via loss of IGFBP expression is not a genetic event that will easily be identified in patient specimens. Although one could envision using immunohistochemistry or quantitative RT-PCR to evaluate for these effects, it is likely that such results will be less clear. Since antibodies targeting IGFIR and small-molecule IGFIR inhibitors are entering the clinic, we 

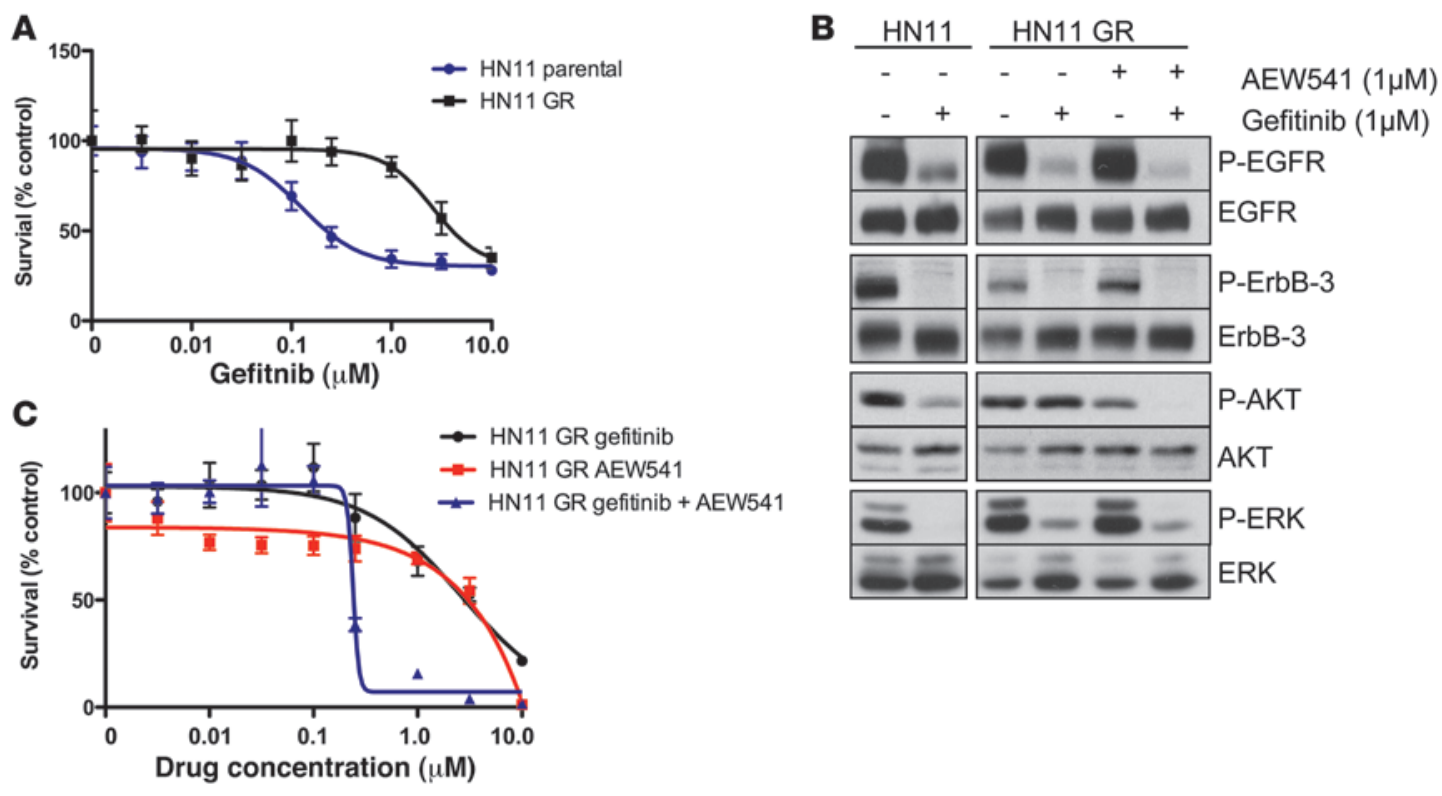

\section{Figure 6}

An independent cell-line model of acquired resistance, HN11 GR, is overcome by combined EGFR and IGFIR blockade. (A) Parental HN11 and HN11 GR cells (see Methods) were subjected to an MTS survival assay in increasing concentrations of gefitinib as in Figure 5. (B) Parental HN11 and HN11 GR cells were treated with the indicated inhibitors for 6 hours and lysed. Lysates were examined by Western blot analyses with the indicated antibodies. (C) Parental HN11 and HN11 GR cells were subjected to an MTS survival assay in increasing concentrations of gefitinib or AEW541 or a combination. When the combination was used, both drugs were used at the identical concentrations during the dose escalation. Error bars show \pm SD.

will likely learn of the effectiveness of combining EGFR and IGFIR inhibitors soon. If clinically tolerated, this combination may be an optimal approach to delaying the onset of resistance as we observed in A431 xenografts. In fact, some combinations of irreversible EGFR TKIs to inhibit T790M, MET inhibitors, and IGFIR antagonists may ultimately find their way to frontline therapy for patients that have EGFR-driven cancers. This approach may eliminate a significant proportion of the tumors that develop acquired resistance and potentially prolong the benefit of anti-EGFR therapy.

\section{Methods}

Cells, plasmids, and reagents. A431 and HN11 cells were obtained from ATCC. A431 Cells were grown in Improved MEM Zn ${ }^{2+}$ Option (Invitrogen) supplemented with $10 \% \mathrm{FBS}$ in a humidified $5 \% \mathrm{CO}_{2}$ incubator at $37^{\circ} \mathrm{C}$. HN11 cells were grown in RPMI (Invitrogen) supplemented with $10 \%$ FBS in a humidified $5 \% \mathrm{CO}_{2}$ incubator at $37^{\circ} \mathrm{C}$. A431 GR and $\mathrm{HN} 11 \mathrm{GR}$ cells were generated by growing parental cells in the presence of increasing concentrations of gefitinib up to $3 \mu \mathrm{M}$. A431-GR2 cells were generated by growing parental A431 cells chronically under gefitinib $(1-3 \mu \mathrm{M})$. To develop the A431 GR, cells were chronically selected in the presence of the EGFR monoclonal antibody cetuximab starting at a concentration of $5 \mathrm{nM}$. This concentration is enough to almost saturate EGFR binding (46). The dose was gradually increased over approximately 8 weeks; cells growing in $100 \mathrm{nM}(15 \mu \mathrm{g} / \mathrm{ml})$ cetuximab were used for subsequent studies. The following drugs were used: gefitinib (AstraZeneca International), erlotinib (Genentech), NVP-AEW541 (provided by Carlos GarciaEcheverria, Novartis), MK-0646 (provided by Michael Chastain, Merck), cetuximab (a gift from Dan Hicklin, ImClone Systems Inc.), and CI-1040 (provided by Judith Leopold-Seboldt, Pfizer). IGFBP-3 was purchased from Apollo Cytokine Research. PI-103 was purchased from Cayman Chemical and LY-294002 from Promega.

IGF-I and IGF-II levels in cell culture supernatants. Conditioned medium from $10^{6}$ cells growing for 24 hours in serum-free conditions was concentrated using centrifugal filter devices (Millipore). Medium was then tested in an enzymatically amplified " 2 -step" sandwich-type immunoassay that measures active IGF-I or IGF-II (Diagnostic Systems Laboratories Inc.) according to the manufacturer's instructions.

Immunoprecipitation and immunoblotting. Cells were washed twice with icecold PBS and lysed in NP40 lysis buffer (20 mM Tris, $150 \mathrm{mM} \mathrm{NaCl}, 1 \%$ NP40, $0.1 \mathrm{mM}$ EDTA, and protease and phosphatase inhibitors). After sonication for 10 seconds and centrifugation (9,400 $\mathrm{g}$ for 10 minutes), protein concentration in the supernatants was measured using the bicinchoninic acid protein assay reagent (Pierce Biotechnology). Immunoprecipitation and immunoblotting were done as described (27) with horseradish peroxidase-conjugated secondary antibodies (Promega). Primary antibodies included the following: EGFR (NeoMarkers), Y1068 p-EGFR, Akt, S473 p-Akt, p-42/44 MAPK, T202/Y204 p-Erk, S6, S235/S236 p-S6, Y1289 p-HER3, and Y1131 p-IGFIR (Cell Signaling Technology); PTEN, HER3, IGFIR $\beta$, IGFBP-3, and IGFBP-4 (Santa Cruz Biotechnology Inc.); IRS-1 and p85 (Millipore); and actin (Sigma-Aldrich).

${ }^{125}$ I-IGF-I ligand blot. $2 \times 10^{6}$ cells were grown for 24 hours in serum-free Improved MEM. Conditioned medium was collected and concentrated 20 -fold by ultrafiltration. Ligand blotting with ${ }^{125}$ I-IGF-I (GE Healthcare) was performed by the method of Hossenlopp et al. (47) as previously described (48).

Cell proliferation assays. Cells were seeded in complete medium in 12-well plates at a density of 25,000 cells/well in triplicate. The next day, cells were washed once with PBS and then cultured for 72 hours in $0.5 \%$ FBS with the indicated drugs or IGFBP-3. After 72 hours, cells were trypsinized and 
A

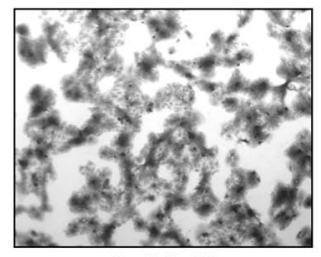

Gef $1 \mu M$

B

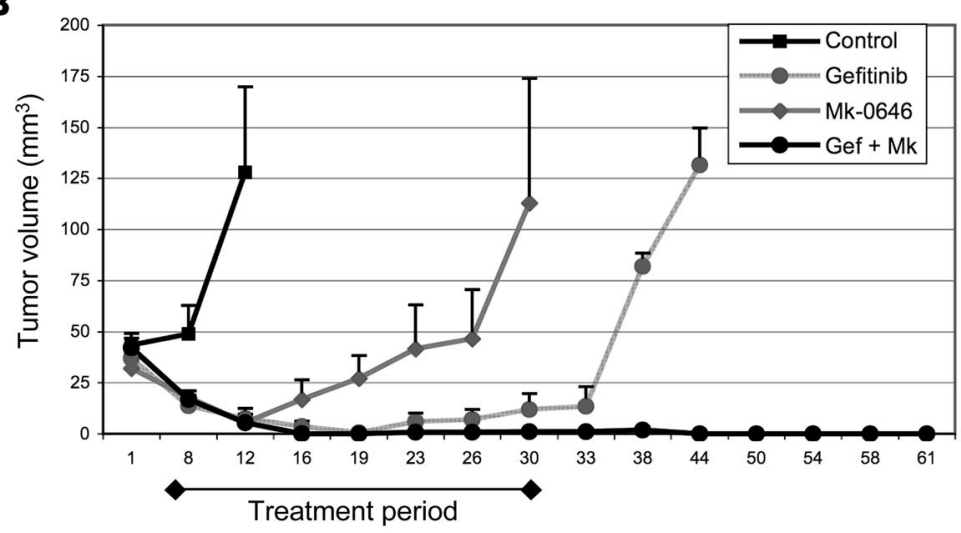

\section{Figure 7}

Inhibition of IGFIR abrogates the emergence of resistance to gefitinib. (A) Parental A431 cells were cultured in regular growth medium with the indicated drugs for 28 days in T-25 flasks. Photographs show the crystal violet staining of the surviving cells after 4 weeks of treatment. Original magnification, $\times 4$. (B) Female athymic mice were injected with parental A431 cells as indicated in Methods. Once tumors reached a volume of approximately $40 \mathrm{~mm}^{3}, 7$ mice per group were randomized to no therapy or treatment with gefitinib (100 mg/kg daily via orogastric gavage), Mk-0646 (500 $\mu \mathrm{g}$ loading dose followed by $250 \mu \mathrm{g}$ i.p. twice a week), or a combination of gefitinib and Mk-0646. Treatment was administered for 30 days. Tumors were measured twice a week with calipers. Data in the figure represent mean tumor volume \pm SD. counted using a Zeiss Coulter Counter (Beckman Coulter). MTS assays were performed (Figures 5 and 6) as previously described (24).

$3 D$ growth assays. Cells were seeded on Growth Factor Reduced Matrigel (BD Biosciences) in 8-well chamber slides following the protocol described by Debnath et al. (49). Drugs were added into the medium 12 hours after cell seeding. Medium and drugs were replenished every 2 days after that. Photographs were taken after culturing the cells for 10 days.

Gene expression profiling. Total RNA was isolated from parental and GR A431 cells using TRIzoL reagent (Invitrogen), followed by RNeasy Mini Kit column purification (QIAGEN) including an in-column DNAse cleanup using RNAse-free DNAse Set (QIAGEN). Synthesis of cRNA target, its hybridization to Human Genome U133 Plus 2.0 microarrays, and scanning of those arrays was performed using Affymetrix GeneChip products and reagents in accordance with the manufacturer's recommendations at the Vanderbilt Microarray Shared Resource. Data were analyzed using GeneSpring Analysis Platform (Agilent Technologies) and filtered via 2-fold expression levels (in at least 2 of the 3 replicates) followed by a $t$ test (variances not assumed equal; $P$ value cutoff of 0.05 ; Benjamini-Hochberg false discovery rate used). The microarray raw data can be accessed at the Gene Expression Omnibus (accession number GSE10696).

IGFBP-3 shRNA. Lentiviral vectors with IGFBP-3 shRNA were purchased from Open Biosystems. We purchased the 5 different shRNA constructs targeting IGFBP-3 and produced viruses, which we used to infect A431 cells. We found that clone ID TRCN0000072508 yielded the best knockdown by Western blot analysis (data not shown). This clone was used for subsequent experiments. Lentivirus production, infection, and puromycin selection $(1 \mu \mathrm{g} / \mathrm{ml})$ were performed as previously described (27). The vector (GFP) and scrambled shRNA controls were the same as previously described (21).

Studies with A431 xenografts. A431 parental cells $\left(4 \times 10^{6}\right)$ were injected subcutaneously in the right flank of 6-week-old female athymic nude mice (Harlan Sprague Dawley Inc.). Tumors were measured twice a week with calipers, and tumor volume in $\mathrm{mm}^{3}$ was calculated according to the following formula: volume $=$ width $^{2} \times$ length $/ 2$. Treatment was started when tumors reached an average volume of approximately $40 \mathrm{~mm}^{3}$. Mice ( $n=7$ per group) were randomized as follows: (a) control; (b) treated with gefitinib $(100 \mathrm{mg} / \mathrm{kg} / \mathrm{day}$ in $0.5 \%$ Tween 20 in PBS by orogastric gavage); (c) treated with the IGFIR antibody MK-0646 (loading dose of $500 \mu \mathrm{g}$ followed by $250 \mu \mathrm{g}$ twice a week i.p.); or (d) treated with gefitinib plus MK-0646. Treatment was stopped after 30 days, and mice were followed up for tumor recurrence. All of the mouse experiments used in this study were approved by the Institutional Animal Care Committee of Vanderbilt University School of Medicine. Mice were housed in the accredited Animal Care Facility of the Preston Research Building of the Vanderbilt University Medical Center and were cared for by Vanderbilt animal care expert personnel and university veterinarians.

\section{Acknowledgments}

This work was supported by NIH grants R01 CA80195 (to C.L. Arteaga) and K08 CA120060-01 (to J.A. Engelman), the American Association for Cancer Research (to J.A. Engelman), the International Association for the Study of Lung Cancer (to J.A. Engelman), Vanderbilt Breast Cancer Specialized Program of Research Excellence (SPORE) grant P50 CA98131 (to C.L. Arteaga), Vanderbilt-Ingram Comprehensive Cancer Center Support grant P30 CA68485 (to C.L. Arteaga), Dana-Farber/Harvard Cancer Center Gastrointestinal Cancer SPORE grant P50 CA127003 (to J.A. Engelman), and a research grant from Merck (to C.L. Arteaga).

Received for publication November 27, 2007, and accepted in revised form April 23, 2008.

Address correspondence to: Carlos L. Arteaga, Division of Oncology, Vanderbilt University Medical Center, 2200 Pierce Avenue, 777 PRB, Nashville, Tennessee 37232-6307, USA. Phone: (615) 936-3524; Fax: (615) 936-1790; E-mail: carlos.arteaga@vanderbilt.edu. Or to: Jeffrey A. Engelman, Massachusetts General Hospital Cancer Center, 149 13th Street, Charlestown, Massachusetts 02120, USA. Phone: (617) 724-7298; Fax: (617) 724-9648; E-mail: jengelman@partners.org.

Anthony C. Faber and Shizhen Emily Wang contributed equally to this work. 
1. Shepherd, F.A., et al. 2005. Erlotinib in previously treated non-small-cell lung cancer. N. Engl. J. Med. 353:123-132.

2. Fukuoka, M., et al. 2003. Multi-institutional randomized phase II trial of gefitinib for previously treated patients with advanced non-small-cell lung cancer. J. Clin. Oncol. 21:2237-2246.

3. Kris, M.G., et al. 2003. Efficacy of gefitinib, an inhibitor of the epidermal growth factor receptor tyrosine kinase, in symptomatic patients with nonsmall cell lung cancer: a randomized trial. JAMA. 290:2149-2158.

4. Perez-Soler, R., et al. 2004. Determinants of tumor response and survival with erlotinib in patients with non-small-cell lung cancer. J. Clin. Oncol. 22:3238-3247.

5. Paez, J.G., et al. 2004. EGFR mutations in lung cancer: correlation with clinical response to gefitinib therapy. Science. 304:1497-1500.

6. Lynch, T.J., et al. 2004. Activating mutations in the epidermal growth factor receptor underlying responsiveness of non-small-cell lung cancer to gefitinib. N. Engl. J. Med. 350:2129-2139.

7. Pao, W., et al. 2004. EGF receptor gene mutations are common in lung cancers from "never smokers" and are associated with sensitivity of tumors to gefitinib and erlotinib. Proc. Natl. Acad. Sci. U. S. A. 101:13306-13311.

8. Mitsudomi, T., et al. 2005. Mutations of the epidermal growth factor receptor gene predict prolonged survival after gefitinib treatment in patients with non-small-cell lung cancer with postoperative recurrence. J. Clin. Oncol. 23:2513-2520.

9. Han, S.W., et al. 2005. Predictive and prognostic impact of epidermal growth factor receptor mutation in non-small-cell lung cancer patients treated with gefitinib. J. Clin. Oncol. 23:2493-2501.

10. Takano, T., et al. 2005. Epidermal growth factor receptor gene mutations and increased copy numbers predict gefitinib sensitivity in patients with recurrent non-small-cell lung cancer. J. Clin. Oncol. 23:6829-6837.

11. Cappuzzo, F., et al. 2005. Epidermal growth factor receptor gene and protein and gefitinib sensitivity in non-small-cell lung cancer. J. Natl. Cancer Inst. 97:643-655

12. Tsao, M.S., et al. 2005. Erlotinib in lung cancer - molecular and clinical predictors of outcome. N. Engl. J. Med. 353:133-144.

13. Engelman, J.A. 2007. The role of phosphoinositide 3-kinase pathway inhibitors in the treatment of lung cancer. Clin. Cancer Res. 13:s4637-s4640.

14. Kobayashi, S., et al. 2005. EGFR mutation and resistance of non-small-cell lung cancer to gefitinib. N. Engl. J. Med. 352:786-792.

15. Pao, W., et al. 2005. Acquired resistance of lung adenocarcinomas to gefitinib or erlotinib is associated with a second mutation in the EGFR kinase domain. PLoS Med. 2:e73.

16. Gorre, M.E., Ellwood-Yen, K., Chiosis, G., Rosen, N., and Sawyers, C.L. 2002. BCR-ABL point mutants isolated from patients with imatinib mesylateresistant chronic myeloid leukemia remain sensitive to inhibitors of the BCR-ABL chaperone heat shock protein 90. Blood. 100:3041-3044.

17. Antonescu, C.R., et al. 2005. Acquired resistance to imatinib in gastrointestinal stromal tumor occurs through secondary gene mutation. Clin. Cancer Res. 11:4182-4190.
18. Kwak, E.L., et al. 2005. Irreversible inhibitors of the EGF receptor may circumvent acquired resistance to gefitinib. Proc. Natl. Acad. Sci. U. S. A. 102:7665-7670.

19. Kosaka, T., et al. 2006. Analysis of epidermal growth factor receptor gene mutation in patients with non-small cell lung cancer and acquired resistance to gefitinib. Clin. Cancer Res. 12:5764-5769.

20. Balak, M.N., et al. 2006. Novel D761Y and common secondary T790M mutations in epidermal growth factor receptor-mutant lung adenocarcinomas with acquired resistance to kinase inhibitors. Clin. Cancer Res. 12:6494-6501.

21. Engelman, J.A., et al. 2007. MET amplification leads to gefitinib resistance in lung cancer by activating ERBB3 signaling. Science. 316:1039-1043.

22. Bean, J., et al. 2007. MET amplification occurs with or without T790M mutations in EGFR mutant lung tumors with acquired resistance to gefitinib or erlotinib. Proc. Natl. Acad. Sci. U. S. A. 104:20932-20937.

23. Ogino, A., et al. 2007. Emergence of epidermal growth factor receptor $\mathrm{T} 790 \mathrm{M}$ mutation during chronic exposure to gefitinib in a non small cell lung cancer cell line. Cancer Res. 67:7807-7814.

24. Engelman, J.A., et al. 2006. Allelic dilution obscures detection of a biologically significant resistance mutation in EGFR -amplified lung cancer. J. Clin. Invest. 116:2695-2706.

25. Yamasaki, F., et al. 2007. Acquired resistance to erlotinib in A-431 epidermoid cancer cells requires downregulation of MMAC1/PTEN and up-regulation of phosphorylated Akt. Cancer Res. 67:5779-5788.

26. Bianco, R., et al. 2003. Loss of PTEN/MMAC1/TEP in EGF receptor-expressing tumor cells counteracts the antitumor action of EGFR tyrosine kinase inhibitors. Oncogene. 22:2812-2822.

27. Engelman, J.A., et al. 2005. ErbB-3 mediates phosphoinositide 3-kinase activity in gefitinib-sensitive non-small cell lung cancer cell lines. Proc. Natl. Acad. Sci. U. S. A. 102:3788-3793.

28. Sebolt-Leopold, J.S., et al. 1999. Blockade of the MAP kinase pathway suppresses growth of colon tumors in vivo. Nat. Med. 5:810-816.

29. Knight, Z.A., et al. 2006. A pharmacological map of the PI3-K family defines a role for p110alpha in insulin signaling. Cell. 125:733-747.

30. Engelman, J.A., Luo, J., and Cantley, L.C. 2006. The evolution of phosphatidylinositol 3-kinases as regulators of growth and metabolism. Nat. Rev. Genet. 7:606-619.

31. Garcia-Echeverria, C., et al. 2004. In vivo antitumor activity of NVP-AEW541-A novel, potent, and selective inhibitor of the IGF-IR kinase. Cancer Cell. 5:231-239.

32. Goetsch, L., et al. 2005. A recombinant humanized anti-insulin-like growth factor receptor type I antibody (h7C10) enhances the antitumor activity of vinorelbine and anti-epidermal growth factor receptor therapy against human cancer xenografts. Int. J. Cancer. 113:316-328.

33. Kurtz, A., Hartl, W., Jelkmann, W., Zapf, J., and Bauer, C. 1985. Activity in fetal bovine serum that stimulates erythroid colony formation in fetal mouse livers is insulinlike growth factor I. J. Clin. Invest. 76:1643-1648.

34. Wakeling, A.E., et al. 2002. ZD1839 (Iressa): an orally active inhibitor of epidermal growth factor signaling with potential for cancer therapy. Cancer Res. 62:5749-5754.
35. She, Q.B., et al. 2005. The BAD protein integrates survival signaling by EGFR/MAPK and PI3K/Akt kinase pathways in PTEN-deficient tumor cells. Cancer Cell. 8:287-297.

36. Mellinghoff, I.K., et al. 2005. Molecular determinants of the response of glioblastomas to EGFR kinase inhibitors. N. Engl. J. Med. 353:2012-2024.

37. Berns, K., et al. 2007. A functional genetic approach identifies the PI3K pathway as a major determinant of trastuzumab resistance in breast cancer. Cancer Cell. 12:395-402.

38. Takaoka, M., et al. 2004. Epidermal growth factor receptor regulates aberrant expression of insulinlike growth factor-binding protein 3. Cancer Res. 64:7711-7723.

39. Grimberg, A., and Cohen, P. 2000. Role of insulin-like growth factors and their binding proteins in growth control and carcinogenesis. J. Cell Physiol. 183:1-9.

40. Torng, P.L., et al. 2007. Insulin-like growth factor binding protein-3 (IGFBP-3) acts as an invasionmetastasis suppressor in ovarian endometrioid carcinoma. Oncogene. 27:2137-2147.

41. Peng, L., Wang, J., Malloy, P.J., and Feldman, D. 2007. The role of insulin-like growth factor binding protein-3 in the growth inhibitory actions of androgens in LNCaP human prostate cancer cells. Int. J. Cancer. 122:558-566.

42. Takaoka, M., et al. 2007. IGFBP-3 regulates esophageal tumor growth through IGF-dependent and independent mechanisms. Cancer Biol. Ther. 6:534-540.

43. Burger, A.M., Leyland-Jones, B., Banerjee, K., Spyropoulos, D.D., and Seth, A.K. 2005. Essential roles of IGFBP-3 and IGFBP-rP1 in breast cancer. Eur. J. Cancer. 41:1515-1527.

44. Tolcher, A.W., et al. 2007. A phase I pharmacokinetic and pharmacodynamic study of AMG 479, a fully human monoclonal antibody against insulin-like growth factor type 1 receptor (IGF-1R), in advanced solid tumors. In Journal of Clinical Oncology 2007 ASCO Annual Meeting Proceedings Part I. June 1-5. Chicago, Illinois, USA. 25:3002.

45. Prieur, A., Tirode, F., Cohen, P., and Delattre, O. 2004. EWS/FLI-1 silencing and gene profiling of Ewing cells reveal downstream oncogenic pathways and a crucial role for repression of insulinlike growth factor binding protein 3. Mol. Cell. Biol. 24:7275-7283.

46. Perez-Torres, M., Guix, M., Gonzalez, A., and Arteaga, C.L. 2006. Epidermal growth factor receptor (EGFR) antibody down-regulates mutant receptors and inhibits tumors expressing EGFR mutations. J. Biol. Chem. 281:40183-40192.

47. Hossenlopp, P., Seurin, D., Segovia-Quinson, B., Hardouin, S., and Binoux, M. 1986. Analysis of serum insulin-like growth factor binding proteins using western blotting: use of the method for titration of the binding proteins and competitive binding studies. Anal. Biochem. 154:138-143.

48. McGuire, W.L., Jr., et al. 1992. Regulation of insulinlike growth factor-binding protein (IGFBP) expression by breast cancer cells: use of IGFBP-1 as an inhibitor of insulin-like growth factor action [erratum 1992, 84:1837]. J. Natl. Cancer Inst. 84 :1336-1341.

49. Debnath, J., Muthuswamy, S.K., and Brugge, J.S. 2003. Morphogenesis and oncogenesis of MCF-10A mammary epithelial acini grown in three-dimensional basement membrane cultures. Methods. 30:256-268. 